\title{
PENINGKATAN KUALITAS PRODUK MANGGA KERING DENGAN TEKNIK DEHIDRASI OSMOSIS DI KABUPATEN INDRAMAYU
}

\author{
Yosini Deliana $^{1}$, Sri Fatimah ${ }^{2}$, Endah Wulandari ${ }^{3}$ dan Edy Suryadi ${ }^{4}$ \\ ${ }^{1,2}$ Department of Agribusiness, Faculty of Agriculture, Universitas Padjadjaran \\ ${ }^{3,4}$ Faculty of Agroindustrial Technology, Universitas Padjadjaran \\ E-mail: y.deliana@gmail.com
}

\begin{abstract}
ABSTRAK. Buah mangga mempunyai daya simpan yang singkat yaitu dalam waktu 3-4 hari setelah matang penuh, daging buah sudah lunak, permukaan kulit buahnya banyak bercak warna coklat akibat penyakit pasca panen. Untuk menekan besarnya kerugian akibat terjadinya kehilangan hasil, maka penanganan pasca panen buah harus benar-benar diperhatikan. Proses diversifikasi produk olahan diharapkan dapat menyelamatkan hasil panen yang berlimpah pada saat panen raya, produk lebih awet dan jangkauan pemasaran lebih luas dengan resiko kerusakan yang lebih kecil. Dehirasi osmosis salah satu cara untuk meningkatkan kualitas produk mangga kering (dried mango). Pelatihan dilakukan dari Juli- September 2018 di UKM Prosomi Desa Majakerta, Balongan dan UKM Secawati Desa Krasak, Kabupaten Indramayu. Pihak yang terlibat dalam ini adalah dosen dan masyarakat. Hasil Pengabdian masyarakat menunjukkan adanya peningkatan pengetahuan peserta dalam tehnik dehidrasi osmosis, pengupasan mangga, pemotongan mangga, hygienis produk dan cara mendapatkan izin edar produk P-IRT.
\end{abstract}

Kata kunci: Dehidrasi osmosis; mangga kering; UKM; peningkatan pendapatan

ABSTRACT. Mangoes have a short shelf life that is 3-4 days after full ripe, the fruit flesh is soft, the surface of the fruit skin has many brown spots due to post-harvest disease. To reduce the amount of losses due to loss of yield, the handling of post-harvest fruit must be really considered. While through the process of diversification of processed products, it is expected to save abundant yields at the time of the harvest, the product is more durable and the marketing range is wider with less risk of damage. Osmosis dehydration is one way to improve the quality of dried mango. The training was conducted from July to September 2018 in the Prosomi UKM of Majakerta Village, Balongan and UKM Secawati Krasak Village, Indramayu Regency. The parties involved are lecturers, and the community. The results of community service show an increase in the knowledge of participants in the techniques of dehydration osmosis, mango stripping, mango cutting, hygienic types of products to get PIRT

Key words: Dehidrasi osmosis; dried mango; Small Medium entrepresis; increasing income

\section{PENDAHULUAN}

Klaster industri pengolahan buah di Jawa terutama Kabupaten Cirebon di fokuskan pada pengambangan komoditas puree mangga, kabupaten Majalengka di fokuskan pada pengembangan pasca panen buah dalam kemasan yang representative, kabupaten Indramayu difokuskan untuk mengembangkan industri industri produk olahan berbasis mangga dalam bentuk manisan kering dan Kabupaten Kuningan difoukuskan untuk pengembangan industri pengolahan buah dalam bentuk juice buah, industri konsentrat buah, industri sirup buah dan industri lainnya(Triani \& Ariffin 2019) Persentase varietas mangga di kabupaten Majalengka, Cirebon dan Indramayu pada Tabel 1.

Tabel 1.Persentase Varietas Mangga di Kabupaten Majalengka, Cirebon dan Indramayu

\begin{tabular}{cccc}
\hline $\begin{array}{c}\text { Varieties of } \\
\text { Mangos }\end{array}$ & $\begin{array}{c}\text { Majalengka } \\
(\%)\end{array}$ & $\begin{array}{c}\text { Cirebon } \\
(\%)\end{array}$ & $\begin{array}{c}\text { Indramayu } \\
(\%)\end{array}$ \\
\hline Gedong Gincu & 11 & 45 & 35 \\
Harum manis & 18 & 37 & 30 \\
Cengkir & 20 & 11 & 50 \\
Lainnya & 21 & 7 & 15 \\
\hline
\end{tabular}

(Anon 2016)

Dari Tabel 1 terlihat bahwa varieras cengkir terbangak di Kabupaten Indramayu dan merupakan icon
Indramayu. Mangga cengkir Indramayu mempunyai karakteristik yang baik untuk dijadikan sebagai bahan baku manisan mangga kering dilihat dari sifat fisik dan kimanya, terutama dari warna, rendemen daging serta kadar serat yang rendah $(0,75 \%)$. Namun bila dilihat dari karakteristik kimia, kadar air manisan mangga kering yang dihasilkan masih diatas kadar air standar. Kadar air yang masih tinggi ini diakibatkan oleh kurang stabilnya proses pengeringan. Sektor pertanian pertumbuhannya paling rendah (tumbuh $3 \%$ pertahun- di bawah pertumbuhan ekonomi nasional), oleh sebab itu harus ada disparitas pertumbuhan antara sektor pertanian dan sektor lainnya (Raghavi et al. 2018). Fenomena ini menunjukkan bahwa petani masih belum sejahtera. Untuk mensejahterakan produsen pengolah mangga maka perlu terobosan dengan pemanfaatan teknologi yang berorientasi Pro Poor Technology. Penelitian ini sangat penting dilakukan karena bisa melibatkan penthahelix yaitu akademisi, pelaku bisnis, masyarakat, pemerintah dan media melalui metode penelitian participatoty market chain approach (PMAC) (Triani \& Ariffin 2019).

TujuandariPKMiniadalahuntukmensosialisasikan proses/teknik pembuatan mangga kering (dried mango) dengan dehidrasi osmosis sehingga produk mangga kering yang dihasilkan oleh KWT Secawati dapat meningkat mutunya. 


\section{METODE}

Kegiatan ini dilaksanakan pada bulan JuliSeptember 2018 di UKM Prosomi Desa Majakerta, Balongan dan UKM Secawati Desa Krasak, Kabupaten Indramayu. UKM Prosomi selama ini memproduksi sirup buah mangga gedong gincu dan sudah memiliki pangsa pasar hingga Cirebon dan Bandung, sedangkan KWT Secawati merupakan kelompok petani wanita mangga yang bergerak di bidangnusaha pengolahan mangga. Desa Pihak yang terlibat dalam ini adalah dosen, dan masyarakat. Secara umum pelaksanaan kegiatan ini terbagi dalam dua tahap yaitu pelatihan dan pendampingan pengembangan usaha. Uraian kegiatan tersebut adalah:

1. Pembinaan usaha, dalam kegiatan ini masyarakat di dorong untuk membuat inovasi produk. Sebuah inovasi dapat diterima dan digunakan oleh peserta melalui sebuah proses adopsi yaitu :

\section{a. Awareness (kesadaran)}

Masyarakat sadar semakin sulitnya mencari pekerjaan karena mereka tidak memiliki kompetensi dan keterampilan khusus, sehingga mereka sangat membutuhkan cara yang mudah dan sederhana untuk mendapatkan penghasilan tambahan. Mereka juga mengalami secara langsung sulitnya mendapatkan penghasilan tambahan sekarang ini, sedangkan kebutuhan terus bertambah.

\section{b. Interest (ketertarikan)}

Masyarakat mulai paham dan tertarik untuk mengatasi lingkungan. Dengan melestarikan lingkungan dan memanfaatkan produksi buah mangga yang melimpah menjadi produk yang bernilai. Peserta akan mendapatkan penghasilan mandiri, mengurangi pengangguran dan tidak lagi meresahkan masyarakat.

\section{c. Evaluation (evaluasi)}

Masyarakat akan mengevaluasi tindakan apa yang paling mudah, murah serta memungkinkan untuk mengatasi permasalahan lingkungan serta sekaligus menjadi sarana untuk mencoba mencari penghasilan tambahan

\section{d. Trial (mencoba-coba)}

Masyarakat mencoba membuat produk yang mudah dibuat dengan teknologi tepat guna. Dengan PKM ini peserta akan diajarkan mulai dari mengolah mangga, menjadikan produk buah mangga kering yang lebih tinggi nilai jualnya

\section{e. Adoption (menerapkan)}

Pada tahapan ini peserta sudah yakin untuk memproduksi buah mangga kering. Pada tahapan ini juga mereka sudah mulai mencoba untuk menjadikan bisnis produk ini sebagai lahan bisnis dalam mendapatkan penghasilan tambahan

Adapun rincian metode yang digunakan dalam kegiatan ini sebagaimana dalam Tabel 2.
Tabel 2. Metode Yang Digunakan

\begin{tabular}{|c|c|c|c|}
\hline \multirow{2}{*}{ No } & \multirow{2}{*}{ Kegiatan } & \multicolumn{2}{|c|}{ Keterlibatan dalam kegiatan } \\
\hline & & Dosen & Masyarakat \\
\hline 1 & Survey & $\begin{array}{l}\text { Pendampingan dan } \\
\text { Pengarahan materi } \\
\text { survey }\end{array}$ & Peserta \\
\hline 2 & $\begin{array}{l}\text { Pelatihan } \\
\text { Dehidrasi } \\
\text { Osmosis }\end{array}$ & Pemberian materi & Peserta \\
\hline 3 & $\begin{array}{l}\text { Penyuluhan/ } \\
\text { penyadaran akan } \\
\text { cara produksi } \\
\text { pangan yang } \\
\text { baik dan benar } \\
\text { (CPPB-IRT) }\end{array}$ & Pemberian materi & Peserta \\
\hline 4 & $\begin{array}{l}\text { Pelatihan } \\
\text { pembuatan dried } \\
\text { mango }\end{array}$ & $\begin{array}{l}\text { Melakukan } \\
\text { pelatihan } \\
\text { pembuatan produk } \\
\text { dried mango }\end{array}$ & Peserta \\
\hline 5 & Pendampingan & $\begin{array}{l}\text { Pendampingan dan } \\
\text { pengarahan }\end{array}$ & $\begin{array}{l}\text { Pendampingan } \\
\text { program } \\
\text { kegiatan. }\end{array}$ \\
\hline 6 & Evaluasi & Evaluasi kegiatan & $\begin{array}{l}\text { Membantu } \\
\text { merealisasikan } \\
\text { program kegiatan }\end{array}$ \\
\hline
\end{tabular}

\section{HASIL DAN PEMBAHASAN}

Teknik dehidrasi osmosis yang dilakukan sebagai berikut :

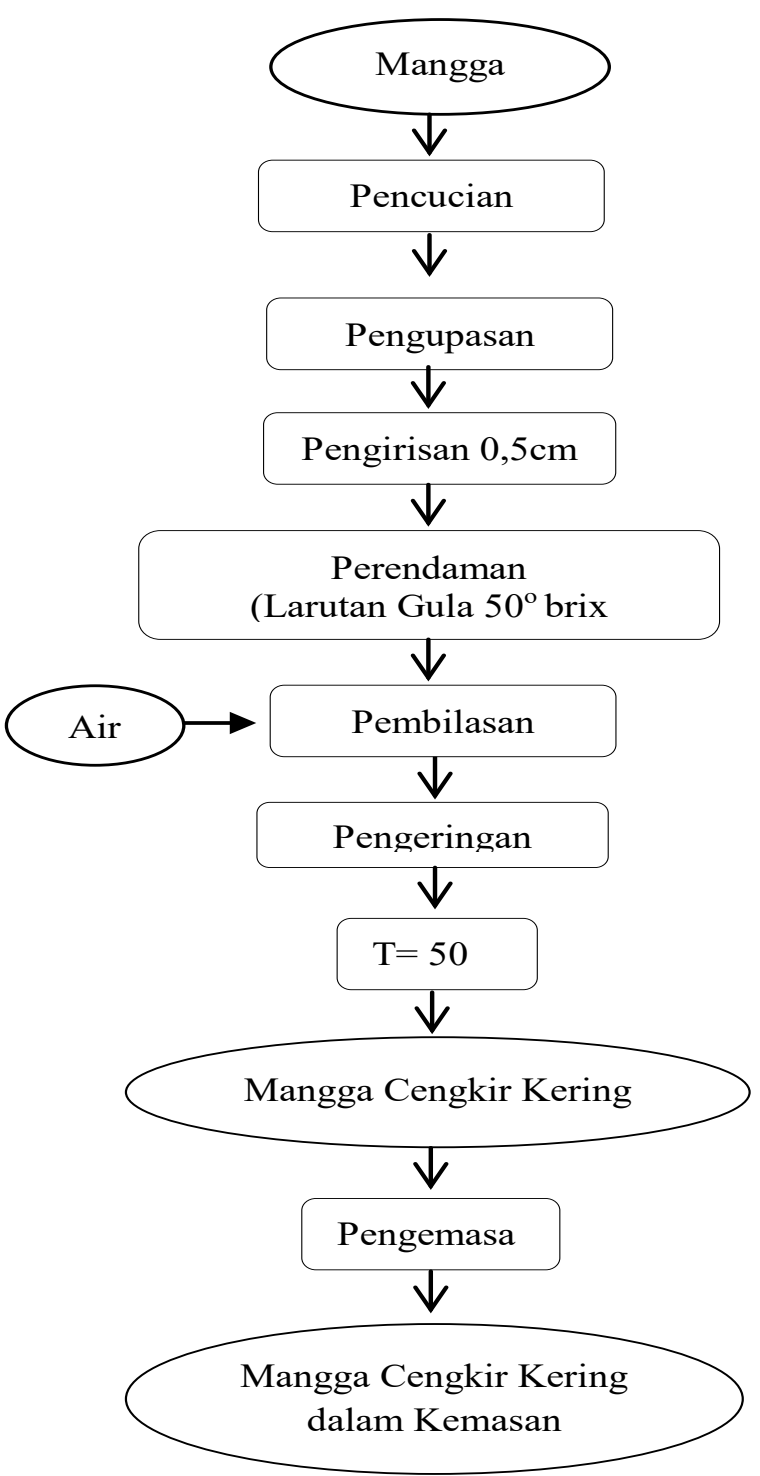


Tabel 3. Syarat Mutu Manisan Kering Buah-buahan (SNI. 0718-83 2005)

\begin{tabular}{lc}
\hline \multicolumn{1}{c}{ Uraian } & Persyaratan \\
\hline $\begin{array}{l}\text { Keadaan (penampakan, bau, } \\
\text { rasa dan jamur) }\end{array}$ & Normal, tidak berjamur \\
Kadar Air & Maksimum $25 \%$ (b/b) \\
Jumlah gula (dihitung sebagai & Minimum $40 \%$ (b/b) \\
sukrosa) & Tidak ada \\
Pemanis buatan & Yang diizinkan untuk makanan \\
Zat warna & Tidak ada \\
Benda asing & Maksimum $50 \mathrm{mg} / \mathrm{kg}$ \\
Bahan larutan sulfit (dihitung & \\
sebagai SO ${ }_{2}$ & \\
Cemaran Logam : & Maksimum $50 \mathrm{mg} / \mathrm{kg}$ \\
- Tembaga (Cu) & Maksimum $2.5 \mathrm{mg} / \mathrm{kg}$ \\
- Timbal (Pb) & Maksimum $40 \mathrm{mg} / \mathrm{kg}$ \\
- Seng (Zn) & Maksimum $150 \mathrm{mg} / \mathrm{kg}$ \\
- Timah & Maksimum $1 \mathrm{mg} / \mathrm{kg}$ \\
- Arsen & Tidak ada \\
Pemeriksaan mikrobiologi : & - \\
- Bakteri Esceherrichia coli & yang berlaku $(\mathrm{APM} / \mathrm{ml})$ \\
\hline
\end{tabular}

(Anon 2016)

Pelatihan dehidrasi osmosis untuk meningkatkan kualitas mangga kering sangat diminati perserta. Peserta selain mengetahui teknik pengolahan mangga kering juga mengetahui pentingnya PIRT dalam mengembangkan usahanya. Adapun cara mengurus PIRT sebagai berikut :

Tahap pertama yang harus diikuti dan dipenuhi persyaratannya oleh pihak UKM adalah mendaftar ke Dinas Kesehatan setempat, tempat UKM berada. Persyaratan yang harus dibawa antara lain Nama Produk yang akan dibuatkan izin edarnya, Merk produk, Alamat produksi, Komposisi bahan yang digunakan dalam menghasilkan produk, Berat produk per kemasan edar, Tangga Kadaluarsa yang dibuktika dengan sertifikat hasil uji dari Laboratorium yang diakui oleh pihak Dinas Kesehatan serta Kode produksi untuk memudahkan pemantauan produk saat di edarkan.

Tahap kedua yang akan dilalui oleh pihak UKM adalah saat mengajukan surat permohonan mendapatkan p-IRT adalah sanggup mengikuti penyuluhan keamanan pangan dan bentuk Cara Produksi Pangan yang Baik untuk skala Industri Rumah Tangga. Sertifikat telah mengikuti pelatihan CPPB-IRT ini yang akan menjadi dasar penerbitan nomor P-IRT produk. Proses pelatihan ini akan diikuti sekitar 30 orang peserta setiap batch-nya. Untuk mengetahui kapan proses pelatihan ini berlangsung, pihak UKM harus sering berkonsultasi dengan pihak Dinas Kesehatan setempat agar dapat mengikuti pelatihan di waktu yang memungkinkan bagi UKM tersebut.

Materi pelatihan yang akan diberikan oleh pihak Dinas Kesehatan meliputi, bagaimana cara memilih bahan baku pangan dan berapa dosis yang diperbolehkan jika menggunakan Bahan Tambahan Pangan. Mempelajari modul Pedoman Cara Produksi Pangan yang Baik untuk IRT. Mengetahui potensi penyakit yang mungkin terkandung dalam beberapa bahan baku pangan (Food Borne Disesases) (Lim 2011). Memahami bagaimana cara yangtepatuntukmenjagahygienitas dan sanitas pengolahan pangan di kawasan produksi maupun pada karyawan. Mengetahui isi undang-undang dan pengawasan mutu yang mengatur regulasi kemanan pangan di Indonesia. Mengetahui potensi adanya kontaminasi silang jika produk mengalami proses penyimpanan dan bagaimana cara mengatasinya serta mengetahui jenis-jenis mikroba yang dapat merusak produk atau menyebabkan kerusakan produk secara mikrobiologis (Kechagia et al. 2013).

Tahap ketiga yang akan dilalui adalah membuat jadwal kunjungan pihak Dinas Kesehatan ke tempat produksi UKM untuk melakukan verifikasi data produk dan lokasi. Tujuan dilakukannya kunjungan ke tempat produksi produk adalah untuk melihat secara langsung proses peroduksi produk yang didaftarkan, bahan-bahan baku yang digunakan, jenis peralatan proses produksi yang digunakan terutama tingkat sanitasi dan higienitas ruang produksi maupun karyawan (SDM). Jenis dan kualitas air yang digunakan dalam membuat produk maupun air yang digunakan untuk mencuci peralatan produksi harus bebas dari mikroorganisme E-Coli, karena dapat menyebabkan potensi kerusakan produk pangan (Ahmed et al. 2016).

Nomor P-IRT yang didapatkan dapat diberlakukan untuk produk-produk sejenis UKM tersebut jika menggunakan bahan baku yang sama. Misalnya produk yang mendapatkan nomor p-irt adalah emping jagung, maka produk sejenis yang diproduksi UKM tersebut seperti kerupuk jagung atau marning boleh menggunakan nomor yang sama. Namun jika UKM memproduksi produk pangan lain yang berbeda bahan bakunya maka produk tersebut harus didaftarkan kembali ke Dinas Kesehatan namun tidak perlu mengikuti tahapan-tahapan awal proses pendaftaran produk.

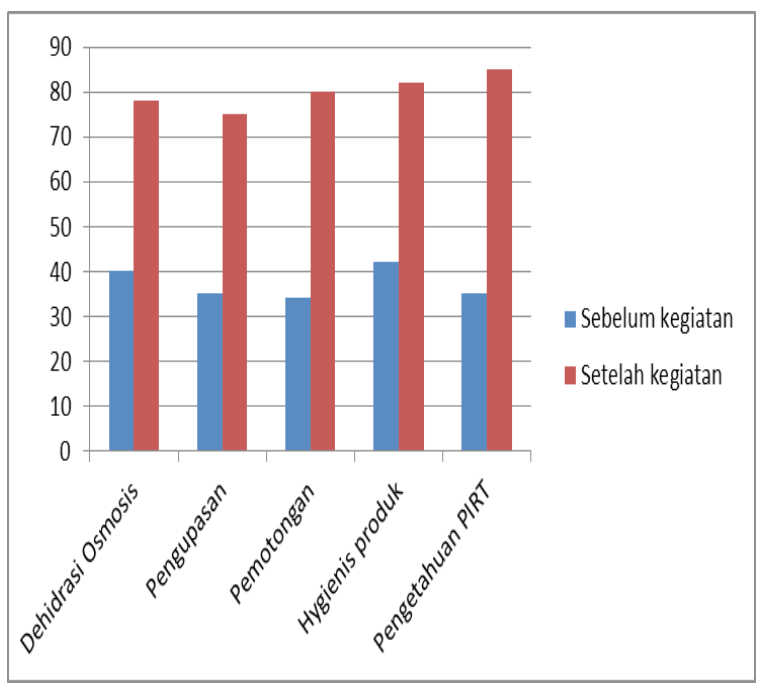

Gambar 1. Pencapaian Hasil PKM 
Tabel 4. Hasil proses penyuluhan yang dicapai selama PPM

\begin{tabular}{|c|c|c|c|}
\hline No. & Indikator & $\begin{array}{c}\text { Base Line } \\
\text { (sebelum kegiatan) }\end{array}$ & Pencapaian setelah kegiatan \\
\hline 1. & $\begin{array}{l}\text { Pengetahuan teknik pengolahan } \\
\text { mangga kering dengan dehidrasi } \\
\text { osmosis }\end{array}$ & $\begin{array}{l}\text { Belum mengetahui bagaimana caranya } \\
\text { meningkatkan kualitas dried mango }\end{array}$ & $\begin{array}{l}\text { Mengetahui teknik dehidrasi osmosis untuk } \\
\text { meningkatkan kualitas mangga }\end{array}$ \\
\hline 2 & $\begin{array}{l}\text { Teknik pengupasan mangga yang pas } \\
\text { untuk produk dried mango }\end{array}$ & $\begin{array}{l}\text { Belum mengetahui teknik pengupasan } \\
\text { mangga untuk dried mango }\end{array}$ & $\begin{array}{l}\text { Sudah mengetahui teknik pengupasan mangga } \\
\text { untuk dried mango }\end{array}$ \\
\hline 3 & $\begin{array}{l}\text { Teknik pemotongan mangga yang } \\
\text { sesuai untuk dried mango }\end{array}$ & $\begin{array}{l}\text { Belum mengetahui teknik pemotongan } \\
\text { mangga untuk dried mango }\end{array}$ & $\begin{array}{l}\text { Sudah mengetahui teknik pemotongan mangga } \\
\text { untuk dried mango }\end{array}$ \\
\hline 4. & Pengetahuan hygienis produk & $\begin{array}{l}\text { Belum mengetahui pentingnya } \\
\text { hygienis produk }\end{array}$ & $\begin{array}{l}\text { Sudah mengetahui } \\
\text { pentingnya hygienis produk }\end{array}$ \\
\hline 5. & Pengetahuan PIRT & $\begin{array}{l}\text { Belum mengetahui cara mendapatkan } \\
\text { PIRT }\end{array}$ & Sudah mengetahui cara mendapatkan PIRT \\
\hline
\end{tabular}

Rencana keberlanjutan program adalah terus mengedukasi terus melakukan pendampingan sampai produknya benar-benar disukai masyarakat, bahkan ber-mimpi untuk bisa eksport. Melakukan pameran untuk mengenalkan produk dan terus melakukan inovasi produk.

\section{SIMPULAN}

Dengan adanya PKM ini pelaku usaha agroindustri atau UKM mengetahui cara untuk meningkatkan kualitas dried mango dengan teknologi sederhana. Selain itu adanya peningkatan pendapatannya diantara anggota UKM

\section{UCAPAN TERIMAKASIH}

Ucapan terima kasih penulis sampaikan ke pihak DRPMi Universitas Padjadjaran yang telah membiayai kegiatan Pengabdian kepada Masyarakat ini.

\section{DAFTAR PUSTAKA}

Ahmed, I., Qazi, I.M. \& Jamal, S. (2016). Developments in osmotic dehydration technique for the preservation of fruits and vegetables. Innovative
Food Science and Emerging Technologies, 34, pp.29-43. Available at: http://dx.doi.org/10.1016/j. ifset.2016.01.003.

Anon, (2016). Thesis. Pengeringan Dan Mutu Manisan Mangga (Mangifera indica, L.) Institut Pertanian Bogor.

Kechagia, M. (2013). Health Benefiots of Probiotics: A Review., 2013.

Lim, J. (2011). Hedonic scaling: A review of methods and theory. Food Quality and Preference, 22(8), pp.733-747. Available at: http://dx.doi. org/10.1016/j.foodqual.2011.05.008.

Raghavi, L.M., Moses, J.A. \& Anandharamakrishnan, C. (2018). Refractance window drying of foods: A review. Journal of Food Engineering, 222, pp.267-275. Available at: https://doi.org/10.1016/j. jfoodeng.2017.11.032.

Triani, F. \& Ariffin, A. (2019). Impact of Climate Variation on Mango (Mangifera indica) Productivity In Indramayu Regency, West Java. PLANTROPICA: Journal of Agricultural Science, 4, (1), 49-56. 